\title{
Monoamine Metabolites Level in CSF is Related to the 5-HTT Gene Polymorphism in Treatment-Resistant Depression
}

\author{
Ikuko Kishida ',2, Eleni Aklillu*,', Chiaki Kawanishi' ${ }^{2}$, Leif Bertilsson' and Hans Ågren ${ }^{3}$ \\ 'Division of Clinical Pharmacology, Department of Laboratory Medicine, Karolinska Institutet, Karolinska University Hospital Huddinge, \\ Stockholm, Sweden; 'Department of Psychiatry, Yokohama City University School of Medicine, Yokohama, Japan; ${ }^{3}$ Section of Psychiatry, \\ Department of Clinical Neuroscience, Karolinska University Hospital Huddinge, Stockholm, Sweden
}

\begin{abstract}
The serotonin (5-hydroxytryptamine) transporter (5-HTT) is considered to affect the pathogenesis of mood disorders. Large number of genetic association studies between 5-HTT functional polymorphisms and vulnerability of mood disorders and therapeutic response to antidepressants has been carried out. We investigated the influence of 5-HTT-linked polymorphic region (5-HTTLPR) and 5-HTT I7 bP variable number of tandem repeat polymorphism (5-HTTVNTR) polymorphisms on concentrations of monoamine metabolites in cerebrospinal fluid (CSF) among treatment-resistant patients with mood disorders. Subjects were 119 Swedish patients with persistent mood disorders and $14 \mathrm{I}$ healthy subjects. In 112 of these patients, we measured 5-hydroxyindoleacetic acid (5-HIAA), homovanillic acid (HVA), and 3-methoxy-4-hydroxyphenylglycol in CSF. Genotyping for 5-HTT polymorphisms from genomic DNA was carried out by PCR. There was no significant difference in allele/genotype frequency between patients and healthy subjects. In patients with mood disorders, we found significant difference in mean 5-HIAA concentration between 5-HTTLPR genotypes $(p=0.03)$. Although the 5-HIAA concentration showed a tendency to be higher in short (S) carriers than in non-S carriers of the 5-HTTLPR in patients $(p=0.06)$, when considering patients with major depressive disorder (MDD), the 5-HIAA concentration was significantly higher among $S$ carriers than among non-S carriers $(p=0.02)$. Moreover, the 5 -HIAA concentration was higher in $S / S$ subjects compared to long $(L) / L(p=0.000 \mathrm{I})$ and $L / S(p=0.002)$ subjects in patients with MDD. Similarly, there was higher HVA concentration in $S / S$ subjects compared to $L / L$ $(p=0.002)$ and $L / S$ subjects $(p=0.002)$. There was no effect of 5-HTTVNTR. Our findings show that the 5-HTTLPR polymorphism affects 5-HIAA and HVA concentrations among treatment-resistant patients with mood disorders.

Neuropsychopharmacology (2007) 32, 2I43-215I; doi:I0.1038/sj.npp. I30I336; published online I4 February 2007
\end{abstract}

Keywords: serotonin transporter; 5-HTTLPR; depression; 5-HIAA; HVA; cerebrospinal fluid

\section{INTRODUCTION}

Ten to twenty percent of patients with recurrent mood disorder develop resistance to standard antidepressant regimens (Crown et al, 2002; Greenberg et al, 2004). Even after several antidepressant treatments, disabling affective symptoms may persist for more than 2 years in these patients. They are the treatment-resistant cases, constituting a substantial problem in current psychiatric practice. Although environmental conditions and psychosocial factors as well as constitutional factors supposedly play roles in the development of treatment resistance, few studies regarding the biological background of these

*Correspondence: Dr E Aklillu, Division of Clinical Pharmacology, Department of Laboratory of Medicine, Karolinska Institutet, Karolinska University Hospital Huddinge, C-168, SE-I4I 86 Stockholm, Sweden, Tel: + 4685858 1056, Fax: + 4685858 1070,

E-mail: eleni.aklillu@ki.se

Received 21 March 2006; revised 19 December 2006; accepted 28 December 2006 factors have been carried out, especially from a genetic point of view.

Over the years, many studies have suggested that the serotonergic system in the brain plays a major role in the pathogenesis of mood disorders (Meltzer and Lowy 1987). The development of antidepressants by the pharmaceutical industry has, to a large extent, targeted serotonin reuptake mechanisms as a means of correcting a surmised serotonergic imbalance. Especially, the serotonin transporter (5-hydroxytryptamine transporter; 5-HTT) located on the presynaptic neuron has been investigated as a way of studying serotonergic neurotransmission in the central nervous system (CNS) (Rudnick and Clark, 1993). Previous studies demonstrated a reduction of the density of serotonin transporter-binding sites in the platelet and the postmortem brain tissue among depressive patients (Nemeroff et al, 1994; Owens and Nemeroff, 1994). Low availability of the serotonin transporter in the dorsal brain stem raphe area was also observed in patients with major depression in a brain-imaging study (Malison et al, 1998). These findings suggested that the function of 5-HTT 
contributes to the pathogenesis of mood disorders. Naturally, several studies investigating the molecular basis of mood disorder have focused on functional polymorphisms of the 5-HTT gene (SLC6A4).

Two functional polymorphisms of the 5-HTT gene have been well investigated in the psychiatric area. The 5-HTT-linked polymorphic region (5-HTTLPR), located $1 \mathrm{~kb}$ upstream of the $5^{\prime}$-flanking regulatory region, consists of a variable number of tandem repeats polymorphism, creating 16 repeats (long: $\mathrm{L}$ ) and 14 repeats (short: S) alleles (Lesch et al, 1996). The $S$ allele of the 5-HTTLPR is supposed to reduce transcriptional efficacy of the promoter, leading to lower expression of the 5-HTT gene in vitro assays (Lesch et al, 1996). Moreover, reduction of 5-HTT availability to $\left[{ }^{123} \mathrm{I}\right] \beta$-CIT was observed in $\mathrm{S}$ carriers in studies, both in vitro and in vivo (Heinz et al, 2002; Little et al, 1998).

The other functional polymorphism, the 5 -HTT $17 \mathrm{bp}$ variable number of tandem repeat polymorphism (5HTTVNTR) located in intron 2, creates STin2.9, STin2.10, and STin2.12 alleles in Caucasians (Ogilvie et al, 1996). These alleles act as transcriptional regulatory elements of 5-HTT gene in mouse embryonic cell, and STin 2.12 was suggested to have stronger activity as an enhancer than STin2.10 (Fiskerstrand et al, 1999; MacKenzie and Quinn, 1999). A large number of genetic association studies between these 5-HTT functional polymorphisms and vulnerability of mood disorders has been reported. Moreover, pharmacodynamic studies suggest a possible association between these polymorphisms and therapeutic responses to antidepressants. Therefore, we think that these 5-HTT functional polymorphisms are of great interest in investigating treatment-resistant mood disorders.

On the other hand, the effect of 5-HTT functional polymorphisms on serotonergic neurotransmission in human has not been well characterized. Concentrations of monoamine metabolites such as 5-hydroxyindoleacetic acid (5-HIAA), homovanillic acid (HVA), and 3-methoxy-4hydroxyphenylglycol (MHPG) in cerebrospinal fluid (CSF) are suggested to reflect monoamine turnover in the CNS (Stanley et al, 1985). In nonhuman primate studies, genetic as well as environmental factors contribute to the serotonin turnover rate (Clarke et al, 1996; Higley et al, 1993). Some studies suggested that 5-HTTLPR polymorphisms moderate other monoamine metabolites, such as MHPG and HVA. Jonsson et al (1998) reported the relationship between 5-HTT polymorphisms and MHPG, although their results were not replicated (Williams et al, 2003). Furthermore, Ågren et al (1986) observed positive correlations between 5-HIAA and HVA in CSF and suggested a unidirectional relationship between 5-HIAA and HVA, from the former to the latter.

In the present study, we performed a systematic genotyping for 5-HTTLPR and 5-HTTVNTR polymorphisms and measured monoamine metabolites in CSF in a large number of treatment-resistant patients with mood disorders in order to assess genetic association with monoamine turnover. In addition, we assessed genetic association with clinical phenotypes, including severity of affective symptoms, suicidal behaviors, and stress of scores in these patients.

\section{PATIENTS AND METHODS}

\section{Subjects}

Subjects were 119 patients with persistent mood disorders (53 men and 66 women; mean age, 45.0 years, SD, 12.3; 77 patients with major depressive disorder (MDD), 25 patients with bipolar disorder (BP), 11 patients with secondary depression, six with dysthymia and others). All patients were investigated during a 5-day inpatient stay at an affective research unit at Sahlgrenska University Hospital at Mölndal, near Gothenburg, Sweden. The patients were required to have the following conditions: (1) a current major depressive episode that met the criteria of Diagnostic and Statistical Manual for Mental Disorders, fourth edition (DSM-IV); (2) persistent symptoms during a recent episode that did not improve over 8 weeks; and (3) failure to improve after 4-week trials of adequate treatments of more than two antidepressants or mood stabilizers. They were sequentially recruited as described previously (Kawanishi et al, 2004). Patients were interviewed with the Schedule for Affective Disorders (SADS) (Endicott and Spitzer, 1978) extracted to mimic the Hamilton Depression Rating Scale (HDRS) (Endicott et al, 1981; Hamilton, 1967). The SADSextracted HDRS provides estimate of the depressive severity both for the week preceding the investigation (the 'past week') and for the week during the preceding year when the most recent depressive episode was at its most severe (the 'worst week'). This study was approved by the ethics committee of Göteborg University Faculty of Medicine, and informed consent was obtained from all patients.

The ethics committee approved the collection of plasma lymphocytes for molecular biological analyses in patients undergoing clinical investigation for refractory affective disorders. Control subjects were 141 healthy volunteers (47 men and 86 women; mean age, 28.7 years; SD, 7.9) recruited from a project approved by the ethics committee of Karolinska Institutet. All subjects were Caucasians of Nordic origin, mainly from Sweden.

\section{Lumbar Puncture and Analyses of Monoamine Metabolites in CSF}

In 112 patients, we measured monoamine metabolites, 5-HIAA, HVA, and MHPG in CSF. Before lumbar puncture, 99 patients were free from medication for at least 2 weeks. Five patients were free from medication for less than 1 week (one with SSRI, four with other antidepressants), and eight patients were under medication (five with SSRI, three with other antidepressants). CSF was obtained under standardized conditions as described previously (Heilig et al, 2004). Briefly, lumbar punctures were performed in the morning with the patients remaining in bed after the night, in the L3/L4 or L4/L5 interspace. A volume of $12 \mathrm{ml}$ of CSF was collected in silicone-coated tubes. No protease inhibitors were added, as we repeatedly found that no measurable degradation occurs when the procedures described here are followed. CSF samples were centrifuged at $2000 \mathrm{~g}, 8^{\circ} \mathrm{C}$, for $10 \mathrm{~min}$ to remove cells and other insoluble material, aliquoted to eliminate the need for repeated freezing and thawing, and stored at $80^{\circ} \mathrm{C}$ before biochemical analyses. Dopamine metabolite HVA, serotonin metabolite 5-HIAA, and noradrenaline metabolite MHPG were routinely 
analyzed by using a mass fragmentographic method, as described previously (Blennow et al, 1993).

\section{Genotype Analysis}

Genomic DNA was extracted from peripheral white blood cells from all subjects using standard techniques. Polymerase chain reaction analyses were performed to determine 5-HTTLPR and 5-HTTVNTR genotypes according to Nakamura et al (2000) or Ogilvie et al (1996), respectively. Genetic analyses were performed by an investigator kept unaware of the clinical profiles of the subjects.

\section{Statistical Analysis}

Statistical analyses were performed using $\chi^{2}$ tests with the Monte Carlo method or Fisher's exact test to determine the presence of allelic and/or genotypic differences. ANCOVA was performed to assess genetic associations with concentrations of monoamine metabolites in patients with mood disorder. As the concentrations of monoamine metabolites in CSF have been considered to be influenced by several demographic variables (Jonsson et al, 1996), we adjusted data by body height that might conceivably confound relationships with CSF data. Two dummy variables, based on the presence/absence of each high-risk allele (Serretti et al, 1999), that is, short allele (S) for 5-HTTLPR and 12 VNTR (12) for 5HTTVNTR, were used to compare the effect of these alleles on CSF monoamine metabolite concentration. Multiple regression analyses were performed to evaluate possible associations between concentrations of monoamine metabolites and independent variables (height, weight, age, sex, 5-HTTLPR, and 5-HTTVNTR genotypes) and to assess the association between 5-HIAA and HVA concentrations. We used ANOVA to assess variations in HDRS scores and SADS scores between 5-HTT genotypes. These analyses were performed using SPSS 10.0 for Windows (SPSS Japan, Tokyo). Pair-wise linkage disequilibrium and estimated haplotype distribution, and the presence of Hardy-Weinberg equilibrium, were analyzed using ARLEQUIN 2.000 (Schneider and Excoffier, 2000). A $p$-value of less than 0.05 was considered statistically significant in all statistical tests.

\section{RESULTS}

\section{5-HTT Polymorphisms in Patients with Mood Disorders and Healthy Controls}

Patients and healthy subjects did not differ in genotype and allele frequencies for 5-HTTLPR and 5-HTTVNTR polymorphisms (Table 1). There was no deviation from HardyWeinberg equilibrium in either patients $(p=1.000)$ or healthy subjects $(p=0.139)$ for 5-HTTVNTR, or in healthy subjects for 5-HTTLPR $(p=0.733)$, whereas a slight but significant deviation was seen in patients for 5-HTTLPR $(p=0.021)$. Haplotype analysis detected no significant linkage disequilibrium between the 5-HTTLPR and 5HTTVNTR polymorphisms $(p=0.409)$. There was no significant difference in an estimated haplotype distribution between patients and healthy subjects $\left(\chi^{2}(4)=\right.$ $1.545, p=0.909)$.

\section{Monoamine Metabolites in CSF and 5-HTT Polymorphisms}

Table 2 shows the ANCOVA results for comparison between 5-HTT genotypes and the predicted mean concentrations of monoamine metabolites in CSF adjusted by height as a covariate in treatment-resistant patients with mood disorders. In the whole group of patients with mood disorders, we found significant difference in mean 5-HIAA concentration between 5-HTTLPR genotypes $\left(\mathrm{F}_{2,108}=3.61, p=0.030\right)$. 5 -HIAA concentration in $S / S$ subjects was significantly higher than that in L/L subjects $(p=0.011)$. There was no significant difference in the 5-HIAA concentration between $S$ carriers and non-S carriers of the 5-HTTLPR, but the 5-HIAA concentration in $S$ carriers displayed a tendency to be higher than that in non-S carriers $(p=0.06$, Table 2). When only considering patients with MDD, we found an even more significant difference between 5-HTTLPR genotypes $\left(\mathrm{F}_{2,67}=8.50, p=0.001\right)$, and the 5 -HIAA concentration among $S$ carriers was significantly higher compared to non-S carriers of the 5-HTTLPR $(p=0.02$, Table 2$)$. The 5 -HIAA concentration in $\mathrm{S} / \mathrm{S}$ subjects was much higher than that in L/L $(p=0.0001)$ and L/S subjects $(p=0.002$, Figure 1a). The power of the sample was enough to detect a difference of as small as $10 \%$ in CSF metabolite concentration between the different genotype groups (depending on the frequency of the risk allele, considering a power of 0.8 , and an $\alpha$ value of 0.05 , two tailed).

A similar pattern was seen in MDD patients for HVA with a significantly higher mean concentration in $S / S$ subjects compared to L/L $(p=0.002)$ and L/S subjects $(p=0.002$, Figure 1b). In contrast, MHPG concentration did not differ significantly between 5-HTTLPR genotypes. With regard to 5-HTTVNTR, no significant differences in the three concentrations of monoamine metabolites were seen.

We next evaluated the influence of sex on monoamine metabolites in CSF in patients with MDD. Both 5-HIAA and HVA concentrations in women were significantly higher than those in men (mean \pm SD: 5-HIAA $133.0 \pm 46.6$ vs 107.6 $\pm 37.6, \quad t=2.43, \quad p=0.018 ; \quad$ HVA $232.1 \pm 94.7 \quad v s$ $175.4 \pm 87.8, t=2.59, p=0.012)$. Therefore, we analyzed men and women subjects separately. In both male and female subjects, we replicated the same significant differences as with the undivided analyses as for 5-HIAA and HVA concentration differences between 5-HTTLPR genotypes. Among men, both 5-HIAA and HVA concentrations in S/S subjects were significantly higher than in L/L and L/S subjects (Figure 2b). Among women, HVA concentration in $\mathrm{S} / \mathrm{S}$ subjects was significantly higher than in L/L, but there were no significant differences in 5-HIAA concentration between $S / S$ and other genotypes (Figure 2a). We examined the 5-HIAA concentration between subjects with and without $S$ allele, demonstrating a significantly higher 5HIAA in female subjects with the $S$ allele $(p=0.009$, Table 3). However, there was no significant difference in both 5-HIAA and HVA when comparison was carried out based on the presence or absence of the $S$ allele in men. When restricting analysis to only MDD patients, our results did not change when analyzing uncorrected CSF. There was significant difference in 5-HIAA but not HVA. We also saw no change in results after exclusion of patients under any 
Table I Genotypic and Allelic Distribution for

5-HTTLPR, 5-HTTVNTR Polymorphisms in Patients with Treatment Resistant Mood Disorders and Healthy Subjects

\begin{tabular}{|c|c|c|c|}
\hline & $\begin{array}{c}\text { Patients with } \\
\text { mood } \\
\text { disorders } \\
n=119\end{array}$ & $\begin{array}{c}\text { Healthy } \\
\text { subjects } \\
n=|4|\end{array}$ & $\boldsymbol{p}^{\mathrm{b}}$ \\
\hline \multicolumn{4}{|c|}{ 5-HTTLPR genotypic distribution \% } \\
\hline $\mathrm{L} / \mathrm{L}$ & 30.3 & 36.2 & 0.132 \\
\hline L/S & 58.8 & 46.8 & \\
\hline $\mathrm{S} / \mathrm{S}$ & 10.9 & 17.0 & \\
\hline \multicolumn{4}{|c|}{ Allelic distribution \% } \\
\hline L & 59.7 & 59.6 & 1.000 \\
\hline S & 40.3 & 40.4 & \\
\hline \multicolumn{4}{|c|}{ 5-HTTVNTR genotypic distribution \% } \\
\hline $9 / 10$ & 0 & 0.7 & 0.603 \\
\hline $10 / 10$ & 16.0 & 11.3 & \\
\hline $10 / 12$ & 47.9 & 51.8 & \\
\hline $12 / 12$ & 36.1 & 36.2 & \\
\hline \multicolumn{4}{|c|}{ Allelic distribution \% } \\
\hline 9 & 0 & 0.4 & 0.811 \\
\hline 10 & 39.9 & 37.6 & \\
\hline 12 & 60.1 & 62.1 & \\
\hline
\end{tabular}

ancluding major depressive disorder, bipolar disorder, and other mood disorders.

bStatistical comparison to distribution between patients with all mood disorders and healthy subjects using $\chi^{2}$ tests.

medication or free from medication for less than 1 week before lumbar puncture (data not shown).

Eight patients were not free from medication during lumbar puncture because of clinical reasons. There were no significant differences in the genotypic frequencies between patients under medication for less than 2 weeks before lumbar puncture and free from medication at lumbar puncture (genotypic frequency (\%): L/L 33.3 vs 30.4, L/S 53.3 vs $62.5, \mathrm{~S} / \mathrm{S} 13.3$ vs $7.1, p=0.693)$.

The observed significant differences between 5HTTLPR genotypes in CSF 5HIIA and HVA remained the same even after excluding patients under medication (5-HIAA $p=0.001$, HVA $p=0.001$ ), patients under any medication or free from medication for less than 1 week before lumbar puncture (5-HIAA $p=0.001$, HVA $p=0.003$ ), and patients under any medication or free from medication for less than 2 weeks before lumbar puncture (5-HIAA $p=0.001$, HVA $p=0.004)$.

Finally, positive associations of 5-HIAA and HVA with $5 H T T L P R$ genotypes by ANCOVA were confirmed by multiple regression analysis with 5-HTTLPR, 5-HTTVNTR genotypes, height, sex, and age as independent variables. The 5-HTTLPR genotypes were related to not only 5-HIAA $(p=0.036)$ but also HVA $(p=0.041)$ in all patients with
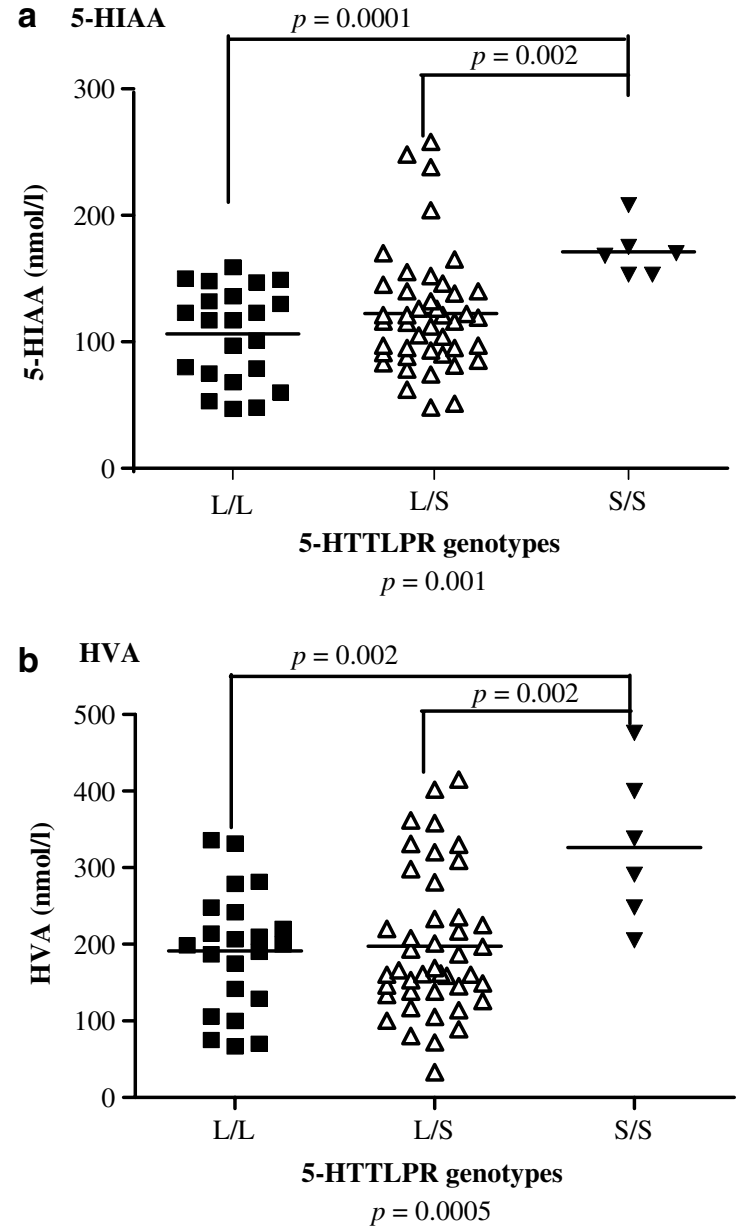

Figure I Comparisons of height-adjusted mean concentrations of CSF monoamine metabolites in different 5-HTTLPR genotypes of patients with MDD, using ANCOVA, adjusted with body height as covariate. Lateral bars show mean for each group (Fisher's post hoc test).

mood disorders. These associations became much more pronounced when only MDD patients were selected (with 5-HIAA: $p=0.002$; with HVA: $p=0.007)$. Multiple regression analyses for HVA with 5-HIAA, height, sex, and age as independent variables also revealed significant correlations between 5-HIAA and HVA concentrations in each 5 -HTTLPR genotype, respectively (S/S, $p=0.015 ; \mathrm{L} / \mathrm{S}$, $p<0.0001 ; \mathrm{L} / \mathrm{L}, p=0.0003)$.

\section{Clinical Phenotypes and 5-HTT Polymorphisms}

We did not find any significant genetic association with the clinical phenotypes. There were no significant differences between 5-HTT genotypes in mean age of onset, in severity of disease measured with HDRS during both PW and WW (Table 4). There were 29 patients whose HDRS scores for WW were equal to scores for PW, thus being through their worst period of depression at the time of the investigation. However, no significant differences could be detected in genotypic distribution between these patients and others who already improved $\left(5-H T T L P R, \chi^{2}(2)=1.164, p=0.617\right.$; 5-HTTVNTR, $\left.\chi^{2}(2)=3.485, p=0.180\right)$. Similarly, there were 
Table 2 Comparisons of CSF Mean Monoamine Metabolites Concentration (nmol/l) in 5-HTTLPR and 5-HTTVNTR Genotypes among Treatment Resistant Patients with Mood Disorders and Major Depressive Disorders

\begin{tabular}{|c|c|c|c|c|c|c|c|c|}
\hline \multirow{2}{*}{$\begin{array}{l}\text { Genotype } \\
\text { 5-HTTLPR } \\
\text { genotype }\end{array}$} & \multicolumn{3}{|c|}{ All mood disorders $(n=I I 2)^{a}$} & \multicolumn{5}{|c|}{ Major depressive disorders $(n=7 I)$} \\
\hline & $\begin{array}{l}\text { Non S carriers } \\
(\mathrm{L} / \mathrm{L})(n=36)\end{array}$ & $\begin{array}{c}\text { S carriers }(S / S, S / L) \\
(n=63)\end{array}$ & $\mathbf{F}$ & $\boldsymbol{p}^{\mathrm{b}}$ & $\begin{array}{l}\text { Non-S carriers } \\
(L / L)(n=22)\end{array}$ & $\begin{array}{c}\text { S carriers }(S / S, S / L) \\
(n=49)\end{array}$ & $\mathbf{F}$ & $p^{b}$ \\
\hline $5-\mathrm{HIAA}$ & $1 \mid 4.8 \pm 7.4$ & $|3| .9 \pm 5.1$ & 3.61 & 0.06 & $103.2 \pm 9.0$ & $129.8 \pm 6.0$ & 8.50 & 0.02 \\
\hline HVA & $199.6 \pm 14.8$ & $216.3 \pm 10.2$ & 0.84 & 0.36 & $185.4 \pm 19.5$ & $216.1 \pm 13.0$ & 1.70 & 0.20 \\
\hline $\begin{array}{l}\text { 5-HTTVNTR } \\
\text { genotype }\end{array}$ & $\begin{array}{l}\text { Non } 12 \text { carriers } \\
(10 / 10)(n=17)\end{array}$ & $\begin{array}{c}12 \text { carriers } \\
(10 / 10)(n=95)\end{array}$ & & & $\begin{array}{l}\text { Non } 12 \text { carriers } \\
(10 / 10)(n=11)\end{array}$ & $\begin{array}{c}12 \text { carriers } \\
(10 / 12,12 / 12)(n=60)\end{array}$ & & \\
\hline $5-\mathrm{HIAA}$ & $118.0 \pm 10.9$ & $128.0 \pm 4.6$ & 0.70 & 0.40 & $114.0 \pm 13.1$ & $122.9 \pm 5.6$ & 0.39 & 0.53 \\
\hline HVA & $205.3 \pm 21.7$ & $212.0 \pm 9.1$ & 0.08 & 0.78 & $199.5 \pm 27.8$ & $207.9 \pm 11.9$ & 0.08 & 0.78 \\
\hline MHPG & $43.2 \pm 2.5$ & $42.8 \pm 1.1$ & 0.02 & 0.88 & $42.5 \pm 2.9$ & $41.1 \pm 1.2$ & 0.20 & 0.65 \\
\hline
\end{tabular}

Data are presented as mean $\pm \mathrm{SE}$.

alncluding major depressive disorder, bipolar disorder, and other mood disorders.

${ }^{b}$ Statistical comparison to predict mean concentrations of monoamine metabolites between 5-HTT genotypes by ANCOVA adjusted by height.

a
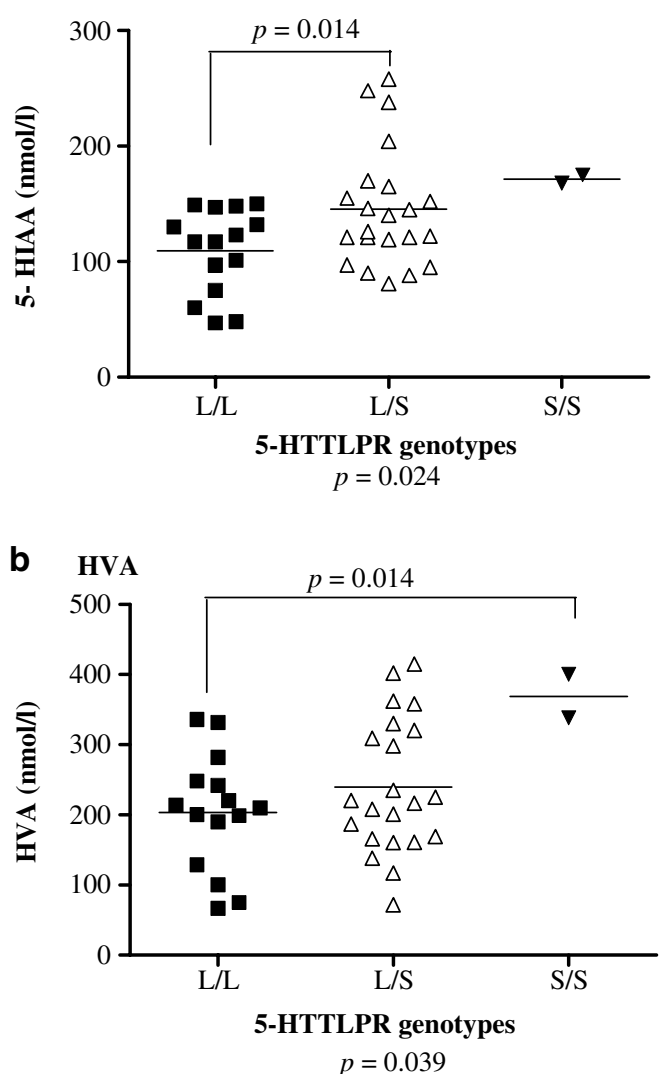

C
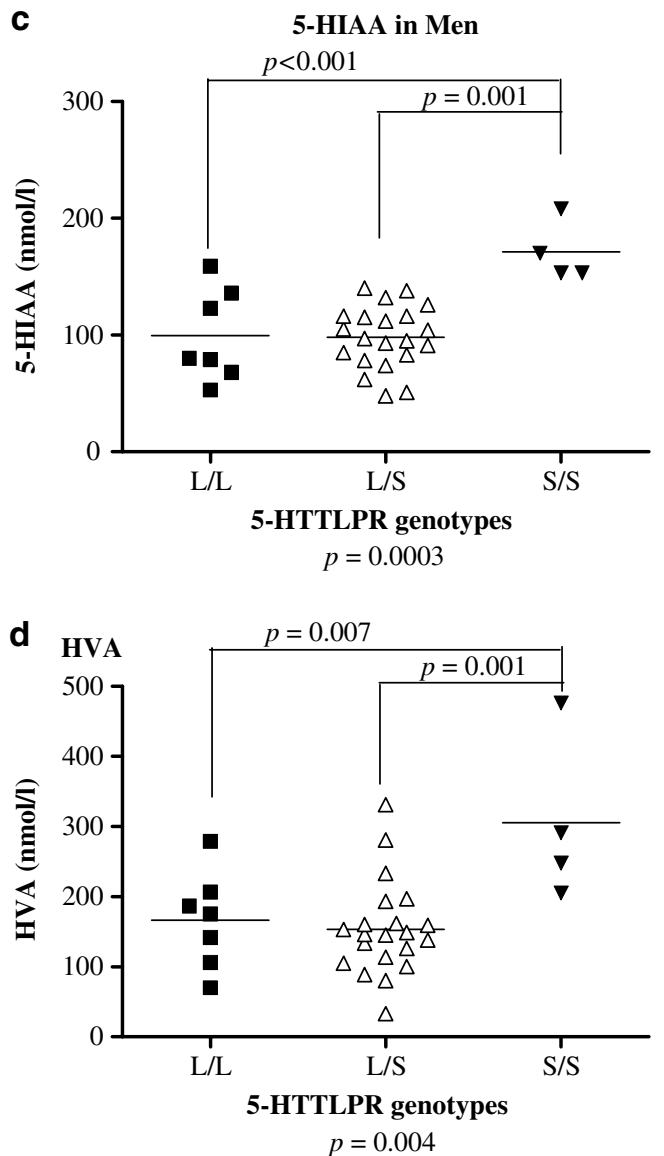

Figure 2 Predicted mean concentrations of monoamine metabolites in 5-HTTLPR genotypes of patients with MDD using ANCOVA adjusted with body height as a covariate. Analyses were performed separately for women (left) and men (right). Lateral bars show mean for each group.

no significant differences in objective and subjective stress scores measured with SADS between 5-HTT genotypes (Table 4). Suicidal ideation during PW or WW, as well as a number of suicidal attempts during current or earlier in life before current depressive episode assessed with SADS did not differ between 5-HTT genotypes (Table 4). 
Table 3 Predicted Concentration (nmol/l) of Monoamine Metabolites in CSF in 5-HTTLPR and 5-HTTVNTR Genotypes among Treatment Resistant Patients with Major Depression

\begin{tabular}{|c|c|c|c|c|c|c|c|c|}
\hline $\begin{array}{l}\text { Genotype } \\
\text { 5-HTTLPR } \\
\text { genotype }\end{array}$ & $\begin{array}{l}\text { Non S carriers } \\
(L / L)(n=7)\end{array}$ & $\begin{array}{c}\text { S carriers } \\
(S / S, S / L)(n=25)\end{array}$ & $\mathbf{F}$ & $\boldsymbol{p}^{\mathrm{a}}$ & $\begin{array}{l}\text { Non S carriers } \\
(L / L)(n=15)\end{array}$ & $\begin{array}{c}\text { S carriers } \\
(S / S, S / L)(n=24)\end{array}$ & $\mathbf{F}$ & $\boldsymbol{p}^{\mathrm{a}}$ \\
\hline 5-HIAA & $100.3 \pm 14.5$ & $109.6 \pm 7.6$ & 0.33 & 0.57 & $108.4 \pm 11.2$ & $148.3 \pm 8.9$ & 7.75 & 0.009 \\
\hline HVA & $167.3 \pm 34.2$ & $177.7 \pm 16.1$ & 0.07 & 0.79 & $201.2 \pm 23.5$ & $251.4 \pm 18.6$ & 2.80 & 0.10 \\
\hline $\begin{array}{l}\text { 5-HTTVNTR } \\
\text { genotype }\end{array}$ & $\begin{array}{l}\text { Non } 12 \text { carriers } \\
(10 / 10)(n=13)\end{array}$ & $\begin{array}{c}12 \text { carriers } \\
(10 / 10)(n=19)\end{array}$ & & & $\begin{array}{l}\text { Non } 12 \text { carriers } \\
(10 / 10)(n=10)\end{array}$ & $\begin{array}{c}12 \text { carriers } \\
(10 / 12,12 / 12)(n=29)\end{array}$ & & \\
\hline 5-HIAA & $84.0 \pm 18.7$ & $111.0 \pm 7.0$ & 1.81 & 0.19 & $136.7 \pm 18.2$ & $132.2 \pm 8.5$ & 0.05 & 0.82 \\
\hline HVA & $172.7 \pm 45.4$ & $175.8 \pm 17.1$ & 0.004 & 0.95 & $226.2 \pm 35.8$ & $233.4 \pm 16.7$ & 0.03 & 0.86 \\
\hline MHPG & $49.2 \pm 4.2$ & $40.4 \pm 1.6$ & 3.93 & 0.06 & $39.6 \pm 3.7$ & $41.5 \pm 1.7$ & 0.21 & 0.65 \\
\hline
\end{tabular}

Data are presented as mean $\pm \mathrm{SE}$.

${ }^{\mathrm{a}}$ Statistical comparison to predict mean concentrations of monoamine metabolites between 5 -HTT genotypes by ANCOVA, adjusted by body height.

Table 4 Comparison with Clinical Data between 5-HTT Genotypes in Treatment Resistant Patients with Mood Disorders

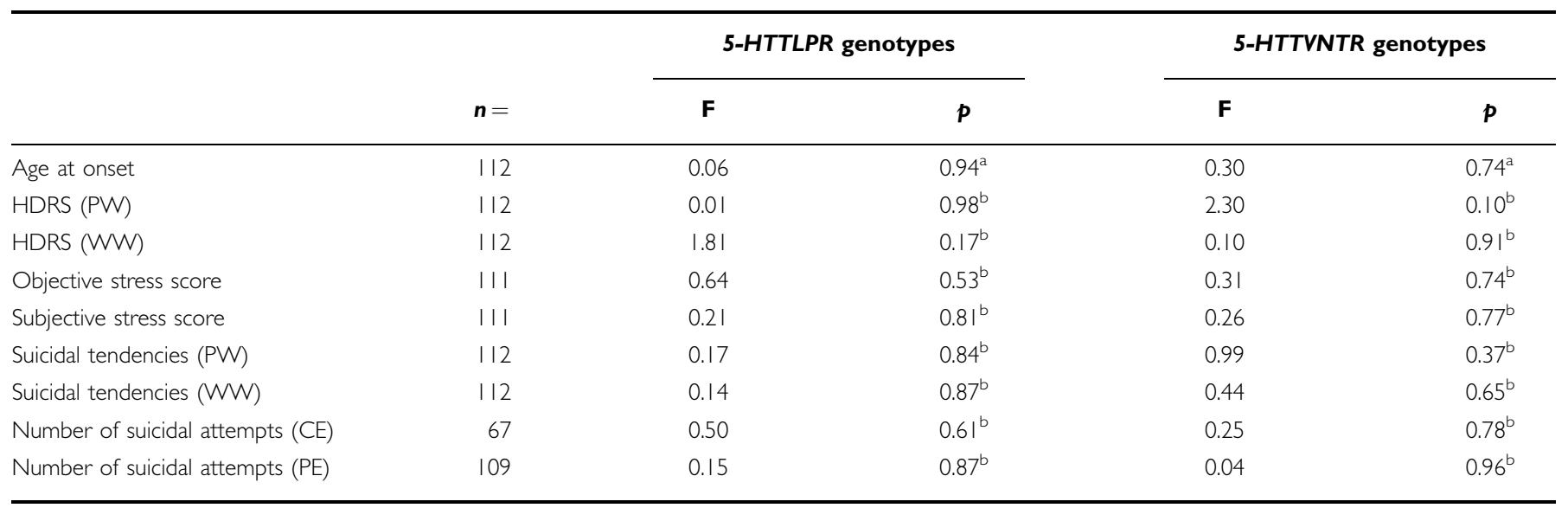

PW, past week; WW, worst week; CE, current episode; PE, previous episode.

Statistical comparison of mean onset age and clinical scores between 5-HTT genotypes using.

${ }^{a}$ ANCOVA adjusted with age as covariates.

${ }^{\text {bOne-way ANOVA. }}$

\section{DISCUSSION}

To our knowledge, this study is the first report showing the 5-HTTLPR polymorphism to be linked with serotonergic status in CNS from patients with mood disorder. In healthy subjects, there were two previous reports investigating the association between monoamine metabolites and 5-HTT polymorphisms. Although one report on African American subjects was consistent with our results (Williams et al, 2003), another on Caucasian subjects differed from ours, reporting higher MHPG in subjects with S/S and 12/12 genotypes (Jonsson et al, 1998). Differences in subject groups, healthy individuals and our patients with mood disorders, may explain the discrepant finding. In the present study, we examined the effects of 5-HTTLPR and 5-HTTVNTR polymorphisms on CSF monoamine metabo- lites in treatment-resistant patients with mood disorders. The results showed a higher concentration of 5-HIAA in S/S genotype compared to $\mathrm{L} / \mathrm{S}$ and $\mathrm{L} / \mathrm{L}$ genotypes. These findings are consistent with the described low-transcriptional activity of the $S$ allele relative to the $\mathrm{L}$ allele and the resulting increased extra cellular serotonin concentration in patients with $S / S$.

Previous studies suggested that the availability of monoamine uptake sites regulates extra cellular monoamine concentrations (Giros et al, 1996; Kreiss and Lucki, 1995). The $S$ allele was supposed to be associated with lower expression of the 5-HTT gene and decreased 5-HTT availability in the dorsal brain stem raphe area (Heinz et al, 2000; Lesch et al, 1996; Little et al, 1998). These findings suggested that $\mathrm{S}$ carriers have low 5-HTT density in nerve endings in the CNS. Accordingly, from our findings 
that there is higher 5-HIAA concentration in patients with the S/S genotype, it is reasonable to assume reduction of 5-HTT density, resulting in increased extracellular serotonin concentration owing to low activity of serotonin reuptake. This hypothesis is supported by previous studies among non-human primates (Heinz et al, 1998) and human males with alcohol dependence (Heinz et al, 2002), in which low serotonin transporter availability in the brainstem was associated with elevated 5-HIAA concentrations. On the other hand, a recent study reported no difference in the 5-HTT binding potential by genotypes in healthy volunteers and in MDDs (Parsey et al, 2006). Contrary to the observation on 5HTT expression studies (Lesch et al, 1996), Hanna et al (1998) reported association of the long variant allele with higher plasma serotonin level. Meanwhile, another recent study showed altered serotonin synthesis and turnover using mice with genetic disruption of 5-HTT (Kim et al, 2005). Thus alternatively, the increased 5-HIAA concentration in S/S genotype could be due to increased serotonin synthesis or turnover.

Interestingly, we found a significant association between 5-HTTLPR genotypes and HVA concentration. Moreover, significant correlations between 5-HIAA and HVA concentrations in each 5-HTTLPR genotype were revealed. A previous study demonstrated and discussed the correlation between 5-HIAA and HVA concentrations in depressive patients and suggested that the influence of dopamine turnover is secondary to the effect on the serotonergic system (Ågren et al, 1986). Our present results would support this hypothesis. In the present study, few subjects were under medication by antidepressants during lumbar puncture. Although still significant differences in 5HIAA and HVA between 5-HTTLPR genotypes and HVA were observed after excluding patients under any medication or free from medication for less than 1 week before lumbar puncture, we could not disregard the effects of medication completely. This is a limitation of our study.

When we divided data for men and women, we found the same significant differences in 5-HIAA and HVA concentration between the 5-HTTLPR genotypes. However, in women subjects, there was no significant difference in 5-HIAA concentration between patients with S/S and other genotypes, probably owing to the small number of women with $\mathrm{S} / \mathrm{S}(n=2)$. On the other hand, the female 5-HIAA concentration was significantly higher than the male. This might be due to differences in sex hormones, which affect serotonin systems.

In the present study, there were no genetic associations between treatment-resistant patients with mood disorders and 5-HTT polymorphisms. Previous studies, including a meta-analysis, have reported an excess of the $S$ allele in depressive patients (Collier et al, 1996; Furlong et al, 1998); however, these positive results are controversial so far (Serretti et al, 2002). In the present study, we found a deviation from Hardy-Weinberg equilibrium in our treatment-resistant patients for 5-HTTLPR, in which the S/S genotype was less frequent than expected in patients. Moreover, the S/S frequency in our patients (10.9\%) was lower than those previously reported (21.6-28.3\%) in Caucasian depressive patients (Smits et al, 2004), whereas allele frequency was consistent. We would surmise that a homogeneous selection bias in our patients with treat- ment-resistant mood disorders could be a possible cause for the observed discrepancy. Decreased concentration of 5-HIAA in CSF was reported in patients with depression (Asberg et al, 1984), and central serotonergic dysfunction has been surmised to be a pathogenesis for affective symptoms. The low frequency of the S/S genotype seen in our treatment-resistant patients, possibly related to high 5-HIAA concentration, might result in a favorable antidepressant response in patients with the S/S genotype. Our finding of lower S/S genotype in treatment-resistant depression is a preliminary finding that needs to be replicated in another study.

Several clinical studies reported the possible association between the $\mathrm{L}$ allele and better antidepressant responses among Caucasian patients (Smits et al, 2004). However, our study was limited to assess a genetic association with drug responses as we did not have detailed information about previous medications for patients and we did not have better antidepressant responders as control subjects to compare with the results shown in treatment-resistant patients.

We assessed clinical phenotypes such as severity of disease, age of onset, stress score, and suicidal behavior in our patients. Especially, we targeted suicidal tendencies as a malignant outcome of treatment resistance. Reduction of 5-HIAA has been linked with special behaviors such as impulsive and suicidal behaviors (Asberg, 1997; Mann, 1998). Therefore, we hypothesized that 5-HTTLPR genotypes, which might relate with both 5-HIAA and HVA, influenced suicidal behavior. However, there were no significant differences between 5-HTT genotypes in any mean scores of suicidal tendencies. This negative result regarding sucidality was in accordance with a recent metaanalysis showing no significant association between 5-HTTLPR genotypes and suicidal attempt in mood disorders (Lin and Tsai, 2004). We assume that other genetic factors together with environmental conditions might influence suicidal tendencies.

In conclusion, our findings suggest that the 5-HTTLPR polymorphism is likely to affect 5-HIAA and HVA concentrations in treatment-resistant patients with mood disorders. The research literature on CSF 5-HIAA and HVA has been beset with discussions on the level of CNS origin for these metabolites. Using the 5-HTT genes as covariates in assessing clinical phenotypical expression would presumably pinpoint the neuronal component of the CSF signals. We suggest the use of a combination of genotypic and endophenotypic information in the assessment of phenotypical links.

Our study has some limitations: first, in spite of the fact that the sample size of our patients was relatively large concerning CSF analysis, the sample power still may not allow a solid association study. Second, our results may be influenced by selection bias, as we used strict criteria for our treatment-resistant patients. In addition, other genetic factors may also affect monoamine turnover. In larger number of subjects, additional genetic studies including a combination of pharmacokinetic and pharmacodynamic results are needed to elucidate genetic factors, which regulate monoamine neurotransmission and the pathological mechanism of genetic predisposition in treatmentresistant mood disorders. 


\section{ACKNOWLEDGEMENTS}

This study was supported by grants from the Swedish Research Council (6604 and 3902); Stockholm County Council research grant (ALF LS 0508-1391), and by $\mathrm{NIH}$ (R01 GM60548). NIH (R01 GM60548). Ikuko Kishida was supported by Eli Lilly Fellowship for Clinical Psychopharmacology.

\section{REFERENCES}

Asberg M (1997). Neurotransmitters and suicidal behavior. The evidence from cerebrospinal fluid studies. Ann N Y Acad Sci 836: 158-181.

Asberg M, Bertilsson L, Martensson B, Scalia-Tomba GP, Thoren P, Traskman-Bendz L (1984). CSF monoamine metabolites in melancholia. Acta Psychiatr Scand 69: 201-219.

Ågren H, Mefford IN, Rudorfer MV, Linnoila M, Potter WZ (1986). Interacting neurotransmitter systems. A non-experimental approach to the 5HIAA-HVA correlation in human CSF. J Psychiatr Res 20: 175-193.

Blennow K, Wallin A, Gottfries CG, Karlsson I, Mansson JE, Skoog I et al (1993). Cerebrospinal fluid monoamine metabolites in 114 healthy individuals 18-88 years of age. Eur Neuropsychopharmacol 3: 55-61.

Clarke AS, Hedeker DR, Ebert MH, Schmidt DE, McKinney WT, Kraemer GW (1996). Rearing experience and biogenic amine activity in infant rhesus monkeys. Biol Psychiatry 40: 338-352.

Collier DA, Stober G, Li T, Heils A, Catalano M, Di Bella D et al (1996). A novel functional polymorphism within the promoter of the serotonin transporter gene: possible role in susceptibility to affective disorders. Mol Psychiatry 1: 453-460.

Crown WH, Finkelstein S, Berndt ER, Ling D, Poret AW, Rush AJ et al (2002). The impact of treatment-resistant depression on health care utilization and costs. J Clin Psychiatry 63: 963-971.

Endicott J, Cohen J, Nee J, Fleiss J, Sarantakos S (1981). Hamilton depression rating scale. Extracted from regular and change versions of the schedule for affective disorders and schizophrenia. Arch Gen Psychiatry 38: 98-103.

Endicott J, Spitzer RL (1978). A diagnostic interview: the schedule for affective disorders and schizophrenia. Arch Gen Psychiatry 35: $837-844$.

Fiskerstrand CE, Lovejoy EA, Quinn JP (1999). An intronic polymorphic domain often associated with susceptibility to affective disorders has allele dependent differential enhancer activity in embryonic stem cells. FEBS Lett 458: 171-174.

Furlong RA, Ho L, Walsh C, Rubinsztein JS, Jain S, Paykel ES et al (1998). Analysis and meta-analysis of two serotonin transporter gene polymorphisms in bipolar and unipolar affective disorders. Am J Med Genet 81: 58-63.

Giros B, Jaber M, Jones SR, Wightman RM, Caron MG (1996). Hyperlocomotion and indifference to cocaine and amphetamine in mice lacking the dopamine transporter. Nature 379: 606-612.

Greenberg P, Corey-Lisle PK, Birnbaum H, Marynchenko M, Claxton A (2004). Economic implications of treatment-resistant depression among employees. Pharmacoeconomics 22: 363-373.

Hamilton M (1967). Development of a rating scale for primary depressive illness. Br J Soc Clin Psychol 6: 278-296.

Hanna GL, Himle JA, Curtis GC, Koram DQ, Veenstra-VanderWeele J, Leventhal BL et al (1998). Serotonin transporter and seasonal variation in blood serotonin in families with obsessivecompulsive disorder. Neuropsychopharmacology 18: 102-111.

Heilig M, Zachrisson O, Thorsell A, Ehnvall A, Mottagui-Tabar S, Sjogren M et al (2004). Decreased cerebrospinal fluid neuropeptide Y (NPY) in patients with treatment refractory unipolar major depression: preliminary evidence for association with preproNPY gene polymorphism. J Psychiatr Res 38: 113-121.
Heinz A, Higley JD, Gorey JG, Saunders RC, Jones DW, Hommer D et al (1998). In vivo association between alcohol intoxication, aggression, and serotonin transporter availability in nonhuman primates. Am J Psychiatry 155: 1023-1028.

Heinz A, Jones DW, Bissette G, Hommer D, Ragan P, Knable M et al (2002). Relationship between cortisol and serotonin metabolites and transporters in alcoholism (correction of alcolholism). Pharmacopsychiatry 35: 127-134.

Heinz A, Jones DW, Mazzanti C, Goldman D, Ragan P, Hommer D et al (2000). A relationship between serotonin transporter genotype and in vivo protein expression and alcohol neurotoxicity. Biol Psychiatry 47: 643-649.

Higley JD, Thompson WW, Champoux M, Goldman D, Hasert MF, Kraemer GW et al (1993). Paternal and maternal genetic and environmental contributions to cerebrospinal fluid monoamine metabolites in rhesus monkeys (Macaca mulatta). Arch Gen Psychiatry 50: 615-623.

Jonsson E, Sedvall G, Brene S, Gustavsson JP, Geijer T, Terenius L et al (1996). Dopamine-related genes and their relationships to monoamine metabolites in CSF. Biol Psychiatry 40: 1032-1043.

Jonsson EG, Nothen MM, Gustavsson JP, Neidt H, Bunzel R, Propping $\mathrm{P}$ et al (1998). Polymorphisms in the dopamine, serotonin, and norepinephrine transporter genes and their relationships to monoamine metabolite concentrations in CSF of healthy volunteers. Psychiatry Res 79: 1-9.

Kawanishi C, Lundgren S, Agren H, Bertilsson L (2004). Increased incidence of CYP2D6 gene duplication in patients with persistent mood disorders: ultrarapid metabolism of antidepressants as a cause of nonresponse. A pilot study. Eur J Clin Pharmacol 59: 803-807.

Kim DK, Tolliver TJ, Huang SJ, Martin BJ, Andrews AM, Wichems $C$ et al (2005). Altered serotonin synthesis, turnover and dynamic regulation in multiple brain regions of mice lacking the serotonin transporter. Neuropharmacology 49: 798-810.

Kreiss DS, Lucki I (1995). Effects of acute and repeated administration of antidepressant drugs on extracellular levels of 5-hydroxytryptamine measured in vivo. J Pharmacol Exp Ther 274: 866-876.

Lesch KP, Bengel D, Heils A, Sabol SZ, Greenberg BD, Petri S et al (1996). Association of anxiety-related traits with a polymorphism in the serotonin transporter gene regulatory region. Science 274: 1527-1531.

Lin PY, Tsai G (2004). Association between serotonin transporter gene promoter polymorphism and suicide: results of a metaanalysis. Biol Psychiatry 55: 1023-1030.

Little KY, McLaughlin DP, Zhang L, Livermore CS, Dalack GW, McFinton PR et al (1998). Cocaine, ethanol, and genotype effects on human midbrain serotonin transporter binding sites and mRNA levels. Am J Psychiatry 155: 207-213.

MacKenzie A, Quinn J (1999). A serotonin transporter gene intron 2 polymorphic region, correlated with affective disorders, has allele-dependent differential enhancer-like properties in the mouse embryo. Proc Natl Acad Sci USA 96: 15251-15255.

Malison RT, Price LH, Berman R, van Dyck CH, Pelton GH, Carpenter L et al (1998). Reduced brain serotonin transporter availability in major depression as measured by [123I]-2 betacarbomethoxy-3 beta-(4-iodophenyl)tropane and single photon emission computed tomography. Biol Psychiatry 44: 1090-1098. Mann JJ (1998). The neurobiology of suicide. Nat Med 4: 25-30.

Meltzer HY, Lowy MT (1987). The serotonin hypothesis of depression. In: Meltzer HY (ed). Psychopharmacology: Third Generation of Progress. Raven Press: New York. pp 513-526.

Nakamura M, Ueno S, Sano A, Tanabe H (2000). The human serotonin transporter gene linked polymorphism (5-HTTLPR) shows ten novel allelic variants. Mol Psychiatry 5: 32-38.

Nemeroff CB, Knight DL, Franks J, Craighead WE, Krishnan KR (1994). Further studies on platelet serotonin transporter binding in depression. Am J Psychiatry 151: 1623-1625. 


\section{5-HIAA and 5-HTT gene polymorphism}

I Kishida et al

Ogilvie AD, Battersby S, Bubb VJ, Fink G, Harmar AJ, Goodwim GM et al (1996). Polymorphism in serotonin transporter gene associated with susceptibility to major depression. Lancet 347: 731-733.

Owens MJ, Nemeroff CB (1994). Role of serotonin in the pathophysiology of depression: focus on the serotonin transporter. Clin Chem 40: 288-295.

Parsey RV, Hastings RS, Oquendo MA, Hu X, Goldman D, Huang YY et al (2006). Effect of a triallelic functional polymorphism of the serotonin-transporter-linked promoter region on expression of serotonin transporter in the human brain. Am J Psychiatry 163: 48-51.

Rudnick G, Clark J (1993). From synapse to vesicle: the reuptake and storage of biogenic amine neurotransmitters. Biochim Biophys Acta 1144: 249-263.

Schneider SRD, Excoffier L (2000). Arlequin: A Software for Population Genetics Data Analysis. Ver 2.000. Genetics and Biometry Lab, Department of Anthropology, University of Geneva, Geneva.
Serretti A, Lattuada E, Catalano M, Smeraldi E (1999). Serotonin transporter gene not associated with psychotic symptomatology of mood disorders. Psychiatry Res 86: 59-65.

Serretti A, Lilli R, Lorenzi C, Lattuada E, Cusin C, Smeraldi E (2002). Serotonin transporter gene (5-HTTLPR) and major psychoses. Mol Psychiatry 7: 95-99.

Smits KM, Smits LJ, Schouten JS, Stelma FF, Nelemans P, Prins MH (2004). Influence of SERTPR and STin2 in the serotonin transporter gene on the effect of selective serotonin reuptake inhibitors in depression: a systematic review. Mol Psychiatry 9: 433-441.

Stanley M, Traskman-Bendz L, Dorovini-Zis K (1985). Correlations between aminergic metabolites simultaneously obtained from human CSF and brain. Life Sci 37: 1279-1286.

Williams RB, Marchuk DA, Gadde KM, Barefoot JC, Grichnik K, Helms MJ et al (2003). Serotonin-related gene polymorphisms and central nervous system serotonin function. Neuropsychopharmacology 28: 533-541. 